\title{
Viewpoint
}

\section{A framework for effective management of change in clinical practice: dissemination and implementation of clinical practice guidelines}

\author{
N T Moulding, C A Silagy, D P Weller
}

\begin{abstract}
Theories from social and behavioural science can make an important contribution to the process of developing a conceptual framework for improving use of clinical practice guidelines and clinician performance. A conceptual framework for guideline dissemination and implementation is presented which draws on relevant concepts from diffusion of innovation theory, the transtheoretical model of behaviour change, health education theory, social influence theory, and social ecology, as well as evidence from systematic literature reviews on the effectiveness of various behaviour change strategies. The framework emphasises the need for preimplementation assessment of (a) readiness of clinicians to adopt guidelines into practice, (b) barriers to change as experienced by clinicians, and (c) the level at which interventions should be targeted. It also incorporates the need for multifaceted interventions, identifies the type of barriers which will be addressed by each strategy, and develops the concept of progression through stages of guideline adoption by clinicians, with the use of appropriately targeted support strategies.

The potential value of the model is that it may enable those involved in the process of guideline dissemination and implementation to direct strategies to target groups more effectively. Clearly, the effectiveness and utility of the model in facilitating guideline dissemination and implementation requires validation by further empirical research. Until such research is available, it provides a theoretical framework that may assist in the selection of appropriate guideline dissemination and implementation strategies.

(Quality in Health Care 1999;8:177-183)
\end{abstract}

Keywords: guidelines; behaviour change theory; conceptual framework

Until recently, there has been little research on the relative merits of dissemination and implementation strategies used to encourage adoption of clinical practice guidelines. However, evidence now exists that use of an appropriate range of strategies, beyond simple information provision through publication in journals or general mailings, can significantly increase rates of guideline adoption by clinicians. ${ }^{1}$

Systematic reviews of the evidence suggest that clinical practice guidelines are most likely to be adopted in practice when dissemination and implementation strategies incorporate several features, including: involvement of enduser clinicians in guideline development; implementation strategies which include a participatory educational intervention; and integration of the guideline into the process of care (for example, re-structuring of medical records). ${ }^{1}$ The most crucial point arising from systematic reviews is that a multifaceted dissemination and implementation strategy is much more likely to increase the probability of uptake in practice than reliance upon a single intervention (box 1). ${ }^{1-5}$

In view of the efficacy of multifaceted strategies, careful planning of a range of dissemination and implementation interventions appropriate to the clinical setting and particular guideline is important. Theory from social and behavioural science can further our understanding of the interplay of factors which influence practitioners to use guidelines, and help to explain why some dissemination and

- Behaviour change is a process

- Change agents must identify with clinicians' concerns

- It is important to assess stage of readiness to change and the specific nature of barriers to change

- Multiple change strategies are more effective than single ones

- Clinician education must include a focus on knowledge, attitudes, and skill development

- Educative strategies must be interactive and participatory

- Social influence can be a powerful behaviour change facilitator or inhibitor

- Environmental support is crucial to the initiation and maintenance of change

Box 1 Key theoretical concepts for encouraging and maintaining guideline adoption 
implementation strategies are more effective than others. Ideally, if a conceptual framework could be developed that predicts which guideline dissemination and implementation strategies might be effective, this may help to provide a model for targeting more effectively the use of individual strategies to maximise their likely effectiveness. We were unable to find any such model in the literature, and therefore sought in this paper to (a) identify relevant theoretical concepts, and (b) apply these ideas to assessing strategies for dissemination and implementation of clinical practice guidelines to create a conceptual framework which may enhance the effective use of such strategies in the future.

\section{Social and behavioural theory}

This paper draws upon five bodies of social and behavioural theory in the development of this conceptual framework:

- Diffusion of innovation theory

- Transtheoretical model of behaviour change

- Aspects of health education theory

- Social influence theory

- Social ecology.

Attempts have been made previously to marry theory and evidence together in relation to encouraging the use of guidelines in practice. For example, Grol has developed a model for implementing change involving a stepwise, cyclical process including identification of obstacles to change and linking of interventions to obstacles. ${ }^{6}$ Robertson et al developed a psychological framework for changing the clinical behaviour of doctors, ${ }^{7}$ whereas Prochaska et al examined stages of change in the context of problem behaviours. ${ }^{8}$ Other work has also examined the broader role of evidence in effecting behaviour change in health care..$^{9-11}$

This paper expands upon this earlier work by suggesting an implementation model for the various theoretical stages of change. It specifically links social and behavioural theory with research on guideline development and implementation.

\section{(1) Diffusion of innovation theory}

Diffusion of innovation theory derives from communication theory, and describes the process by which an innovation is communicated through certain channels over time to members of a social system. ${ }^{12}$ An "innovation" is defined as an idea, practice, or object which is perceived as new. ${ }^{13}$ Four stages of adoption of innovation are identified in this model ${ }^{14}$;

- The knowledge phase involves learning about the innovation

- The persuasion stage involves the individual forming positive or negative attitudes about the innovation

- The individual then tests the acceptability of the innovation in the decision stage

- The final stage is characterised by adoption or rejection of the innovation.

Five different "adopter" categories are identified in the theory, and these are: (1) early innovators, (2) early adopters, (3) an early majority, (4) a late majority, and (5) late adopters. ${ }^{15}$

Diffusion of innovation theory places an emphasis on the role of the "change agent"that is, the individual or individuals who attempt to influence decisions about the adoption of an innovation. It is argued that the change agent must identify with the concerns of the target group. ${ }^{15}$

RELEVANCE TO GUIDELINE DEVELOPMENT AND IMPLEMENTATION

The development of a new guideline is likely to be perceived as an innovation among clinicians. Conroy and Shannon propose that innovators and early adopters, who respond early to guidelines, are likely to include opinion leaders. The early and late majority groups may be more sceptical and more influenced by peers and the opinion leaders, and the late adopters might require extra encouragement in terms of incentives and resources. ${ }^{16}$ They emphasise that ongoing support strategies need to be maintained with clinicians in each of the adopter categories.

Opinion leaders are often used to encourage guideline adoption among practitioners; it is important that they are perceived to identify with the concerns of clinicians, rather than those of outside agencies. Guidelines appear to be more acceptable to physicians if they are endorsed or promoted by a respected peer. ${ }^{17} 18$

Nevertheless, diffusion of innovation theory involves an essentially rational conceptualisation of behaviour, where knowledge and attitude change alone are considered to lead to changed practice. ${ }^{15}$ The role of other factors such as self efficacy (or self confidence) and the need to first develop the necessary skills to undertake behaviour change are not addressed, and this limits application of the theory.

\section{(2) Transtheoretical model of behaviour change}

The transtheoretical model of behaviour change, often referred to as the "readiness to change" model, is a well recognised behaviour change theory with a broader conceptualisation of the factors which influence change. Testing of the model has demonstrated its reliability and effectiveness in improving physicians' practice. ${ }^{8}$ Prochaska and DiClemente suggest that behaviour change is a continual process made up of five main stages ${ }^{19}$ : (1) precontemplation, (2) contemplation, (3) preparation, (4) action, and (5) maintenance. Moving through pre-contemplation to contemplation stages involves changing knowledge and attitudes. Moving from contemplation to preparation and action phases involves changes in emotional processes, positive beliefs about self efficacy to undertake the change, and the development of necessary skills. Progression to the maintenance phase involves restructuring the environment in which the behaviour occurs, and providing social support and reward systems. ${ }^{19}$ 
RELEVANCE TO GUIDELINE DEVELOPMENT AND IMPLEMENTATION

Although the stages of readiness to change in some ways parallel the adopter categories of diffusion of innovation theory, the stages of readiness to change theory embraces the concept of change as a process and emphasises the need to target change strategies appropriately according to individual readiness; in this sense, the transtheoretical model provides better guidance for selecting strategies for guideline dissemination and implementation. The emphasis in this theory on using a range of strategies to encourage change might also help to explain why multifaceted guideline dissemination and implementation have been more successful than single strategies.

Cohen et al draw directly on the readiness to change model to implement guidelines in the United States, assessing groups of practitioners' readiness to change through implementation of a questionnaire followed by targeted intervention strategies. ${ }^{20}$ This evaluative tool might be appropriately modified and applied in other settings to help to determine the proportion of practitioners in each stage and the appropriate mix of dissemination and implementation strategies.

Application of this model leads to the requirement for a more indepth assessment of the exact nature of barriers to the use of particular sets of guidelines; this will help to determine more specifically which strategies are appropriate. Wensing and Grol suggest that practitioners experience a range of such barriers to using guidelines; these include barriers associated with competency such as gaps in knowledge, social barriers such as negative attitudes toward a guideline, or organisational barriers such as a lack of appropriate clinical support. ${ }^{21}$ Assessment of the exact nature of barriers to guideline use might be undertaken through various means, such as surveys of clinicians using questionnaires, interviews, or group consultations. ${ }^{22}$ The use of qualitative methods provides a more detailed and comprehensive picture of individual practitioners' needs. Marshall, for example, ${ }^{23}$ used semistructured interviews and focus groups to determine the main barriers to effective educational interactions between general physicians and specialists. $\mathrm{He}$ found that general practitioners wanted to learn information related to their own practice and to use referrals as a learning tool whereas specialists wanted to concentrate on new developments-educational interventions would therefore have to be different for each group. McColl et al found the main barrier to change for general practitioners in the Wessex region, England was lack of personal time. ${ }^{24}$

\section{(3) Health education theory}

A central tenet of health education theory, and a concept which is incorporated into the transtheoretical model, is that behaviour change cannot take place without attention to gaps in both knowledge and skills. ${ }^{25}$ Green et al argue that a careful assessment must be made of individuals' educational needs in these terms before behaviour change can occur. ${ }^{25}$ Another tenet of health education theory is that the positive impact of education is proportional to the degree of active rather than passive participation of the learner, ${ }^{25}$ and early theory has been expanded to take into consideration policy, regulatory, and organisational influences. Thus, educative processes need to incorporate interactive, participatory elements as well as information provision. Teaching which encourages problem based learning is an example of an interactive approach to developing clinical and diagnostic skills in medicine, and self directed, "evidence-based" approaches to clinical teaching appear to be sustainable over time. $^{26}$

RELEVANCE TO GUIDELINE DEVELOPMENT AND IMPLEMENTATION

In line with the rational conceptualisation of behaviour underpinning the diffusion of innovation theory, competency based barriers to guideline adoption have traditionally been viewed in terms of gaps in practitioners' knowledge about particular guidelines. Efforts to address this have largely involved the provision of printed information or didactic education sessions. These efforts have had limited success. ${ }^{145}$ Health education theory highlights the need for interactive guideline development and implementation strategies; these might include, for example, group discussion rather than reliance on the traditional lecture for information provision. Indeed, a range of implementation strategies are consistent with this model; a reminder for appropriate care, for example, might be considered a reinforcing factor.

\section{(4) Social influence theory}

Social influence theory emphasises the role of others in decision making about behaviour, postulating that factors such as custom, habit, assumptions, and beliefs of peers and prevailing practices and social norms shape the interpretation of information provided through education. ${ }^{27}$ These customs can alter over time and between different locations, so indepth local knowledge is important in making assessments of potential social barriers to guideline adoption. $^{27}$

There is growing interest in the ways in which medical culture determines clinicians' beliefs and how this, in turn, influences practice. For example, the humanistic values of medicine may conflict with the scientific emphasis of evidence-based care; Haines and Rogers argue that a culture of evidence-based practice needs to be developed within the wider context of other important values in medicine, in particular the humanistic values which emphasise holistic, patient centred care, and which draw on the personal and subjective experience of the patient. ${ }^{28}$ Nevertheless, the extent to which these values are constructed dichotomously in medicine may function as an obstacle to clinicians attempting to improve their practice. Further examination of the complexities of medical culture, and how practitioners attempt to accommodate apparently 
competing values, could provide some important insights into the dilemmas facing clinicians in the quest for improved practice.

RELEVANCE TO GUIDELINE DEVELOPMENT AND IMPLEMENTATION

It is important to examine which values and attitudes might operate as social barriers to using guidelines; they are often overlooked when planning guideline dissemination and implementation, and social influence theory can help to expand our understanding of the social processes which influence success of guideline implementation.

The perceived opinions of peers and opinion leaders play a major part in influencing the attitudes of individual practitioners ${ }^{18}$ and, most importantly, their decisions to act on new information. The effects of social influence on the practice of clinicians also involves patients and other health professionals. Other groups with a stake in guidelines include policy makers, researchers, the press, and the healthcare industry (for example, insurers), and their influence should be taken into account when planning guideline development and implementation. $^{29}$

Hence, social influence based strategies for implementing guidelines might include academic detailing (personal visit by a trained person to physicians at their practice), group education, the use of opinion leaders, and mass media education strategies such as publication in journals or campaigns. ${ }^{16}$ Patient mediated interventions such as patient educational materials have been shown to be effective guideline implementation strategies. ${ }^{5}$

The importance of social influence in attitude formation and decisions about practice highlight the importance of building agreement with clinical practice guidelines through consultative processes as part of any implementation strategy. Some studies report that guideline implementation is at times unsuccessful because there are high levels of disagreement or ambivalence over recommendations among practitioners. $^{30}$

The effects of social influence may partly explain why guideline implementation strategies, such as academic detailing and the use of opinion leaders, appear to be relatively effective change strategies in their own right. $^{213132}$ It may also go some way towards explaining why practitioner involvement in adapting guidelines to local contexts increases adoption, along with the sense of ownership that participation provides.

\section{(5) Social ecology theory}

The environmental context within which clinicians practice is a key determinant of guideline adoption. Behavioural theory such as operant conditioning emphasises the importance of the environmental context of behaviour, suggesting that environmental cues and reinforcements are central in encouraging and maintaining behaviour. ${ }^{33}$ The limitation of this approach, however, lies in its tendency to situate the individual as a passive recipient of external sources of feedback. More recent health promotion theory focuses on the interrelationship between individuals and their physical and sociocultural environments. Stokols uses a "social ecological" perspective to describe the process whereby environments influence individual behaviour and, in turn, individuals modify and influence their environments. ${ }^{34}$ Within this approach, interactions are characterised by cycles of mutual influence, where environments have an impact on behaviour, and individuals alter their environments through both individual and collective action. ${ }^{34} \mathrm{~A}$ "synergistic" approach which emphasises multilevel interventions to support change is central to this approach. Thus, behaviour change is more likely to occur and be maintained through complementary social and environmental changes and, in turn, changes in the beliefs and behaviour of individuals strengthens support for social and environmental change. ${ }^{34}$

RELEVANCE TO GUIDELINE DEVELOPMENT AND

IMPLEMENTATION

Environmental and organisational supports which enable and reinforce the use of guidelines operate at two levels. At the clinical level, strategies which integrate guidelines into the process of care, such as reminders provided through computerised decision support systems, have been found to provide important environmental support for change as well as an opportunity for learning new skills and gaining knowledge. $^{35} 36$ Elson and Connelly report various studies which show that practitioner behaviour returns to baseline after withdrawal of computerised decision support, indicating the importance of this type of support. ${ }^{35}$ Attention to organisational support must also include determination of the point at which practitioners require information. For example, reminders will only be effective if not having the information at the point of care is a significant cause of poor performance. ${ }^{3}$ Intensive consultation with practitioners is required to accurately determine appropriate environmental support.

Organisational barriers to guideline adoption also exist beyond the immediate clinical environment. For example, the use of incentives, regulation, and the existence of coordinated programmes for guideline development and implementation can be important determinants of whether guidelines are used in practice. The development of formal guideline development programmes, with a mix of central coordination and local practitioner involvement, appears to maximise the likelihood of adoption in practice. ${ }^{37}$

Assessment of the need for environmental support is clearly of central importance in encouraging guideline adoption, and it is particularly important in relation to the maintenance stage of behaviour change. In line with the social ecology perspective, the provision of environmental support can help to build positive attitudes among individual practitioners which in turn strengthens the push for further social and environmental change conducive to evidence-based practice. 


\section{A conceptual framework for guideline} dissemination and implementation

Based on our review of behaviour change theory, we have identified nine key theoretical concepts which are most relevant to the success of clinical practice guideline development and implementation, and which underpin our conceptual model (box 2). These are that:

- Behaviour change is a process through which practitioners can progress with the help of appropriate interventions which encourage movement from one stage to the next

- Those involved in encouraging the adoption of guidelines among practitioners, the "change agents", must identify with the concerns of clinicians-the involvement of enduser practitioners in the adaptation of guidelines is one way of achieving this

- Assessment of practitioners' stage of readiness to change in terms of adopting guidelines can assist the process of selecting dissemination and implementation strategies

- The specific nature of barriers to change must also be assessed as part of determining appropriate change strategies

- Multiple rather than single methods of guideline dissemination and implementation must be employed based on the premise that practitioners will be in varying stages of change and face various barriers to using guidelines

- Clinician education to encourage guideline adoption must include a focus on knowledge, attitudes, and skill development

- Educative strategies must include interactive and participatory activities

- Social influence in the attitudes of peers and opinion leaders can be a powerful behaviour change facilitator or inhibitor

- Environmental support is central to encouraging and maintaining guideline adoption.

Drawing on these key concepts, as well as evidence from literature reviews on the effectiveness of dissemination and implementation strategies, we have developed a five step conceptual framework for successful guideline dissemination and implementation. The framework incorporates the notion of pre-
The five steps

- Step 1: assessment of practitioner's stage of readiness to change

- Step 2: assessment of specific barriers to guideline use

- Step 3: determination of appropriate level of intervention

- Step 4: design of dissemination and implementation strategies

- Step 5: evaluation of the implementation strategies

Box 2 Steps in the conceptual framework

intervention needs assessment, as well as drawing on the concept of targeting strategies to the individual/group or population level of intervention, based on the work of Lomas and Haynes. $^{38}$ Table 1 outlines the conceptual framework in detail, categorising different dissemination and implementation strategies for intervention level, barriers addressed, and associated stage of change to which each strategy primarily relates. In summary, the five main steps defined by the model are as follows.

STEP 1: ASSESSMENT OF PRACTITIONERS' STAGE OF READINESS TO CHANGE

Assessment of practitioners' stage of readiness to change will help to ensure an appropriate mix of dissemination and implementation strategies. Different types of change strategies should be matched with each stage of readiness to change. An evaluative tool such as that developed by Cohen et al could be given to practitioners to provide feedback on readiness to adopt different sets of guidelines. ${ }^{20}$

\section{STEP 2: ASSESSMENT OF SPECIFIC BARRIERS TO} GUIDELINE USE

Assessment of the specific nature of competency based, social, and organisational barriers to guideline use will further ensure that appropriate strategies are selected. Assessment might be undertaken through various means, such as surveys of clinicians using questionnaires, interviews, or group consultations. The use of qualitative methods will provide a more

Table 1 Conceptual framework for guideline dissemination and implementation

Suggested strategies to assess barriers to change

\begin{tabular}{|c|c|c|}
\hline Stage of readiness to change [19] & Individual/group & Populations \\
\hline \multirow[t]{4}{*}{ Pre-contemplation/contemplation } & Use of local opinion leaders (competence/social) & $\begin{array}{l}\text { Dissemination of clinical practice guidelines through mail, } \\
\text { internet, and/or journal publication (competence) }\end{array}$ \\
\hline & $\begin{array}{l}\text { One-to-one information provision: for example, academic } \\
\text { detailing (competence/social) }\end{array}$ & $\begin{array}{l}\text { Adoption of official policy (for example, the national } \\
\text { cervical screening policy) (competence/social) }\end{array}$ \\
\hline & $\begin{array}{l}\text { Information provision through traditional workshops/conferences } \\
\text { (competence) }\end{array}$ & Use of national opinion leaders (social) \\
\hline & Small group discussions (competence/social) & \\
\hline \multirow[t]{4}{*}{ Preparation/action } & $\begin{array}{l}\text { Innovative continuing medical education (participatory, } \\
\text { facilitation of skills development) (competence/social) }\end{array}$ & $\begin{array}{l}\text { Public education through media campaigns } \\
\text { (competence/social) }\end{array}$ \\
\hline & $\begin{array}{l}\text { Modification of practice environment to enhance decision making } \\
\text { (for example, availability of computer systems) (organisational) }\end{array}$ & $\begin{array}{l}\text { Public education through more interactive, community } \\
\text { based education (competence/social) }\end{array}$ \\
\hline & $\begin{array}{l}\text { Patient education at the clinical level-non-interactive and } \\
\text { interactive (competence/social) }\end{array}$ & Government regulation (organisational/social) \\
\hline & $\begin{array}{l}\text { Enduser involvement in guideline development/adaptation } \\
\text { (competence/social) }\end{array}$ & \\
\hline \multirow[t]{4}{*}{ Maintenance } & Audit and feedback (organisational/social/competence) & Feedback on practice pattern data (competence/social) \\
\hline & Peer review (competence/social) & Feedback on health outcomes data (competence) \\
\hline & $\begin{array}{l}\text { Reminder systems (for example, using support staff, computer } \\
\text { generated reminders) (organisational) }\end{array}$ & Mailed reminders to clinicians/patients (organisational) \\
\hline & Computerised records systems (organisational) & \\
\hline
\end{tabular}


detailed and comprehensive picture of practitioners' needs. Other relevant groups such as patients, other health professionals, and opinion leaders might also be consulted.

STEP 3: DETERMINATION OF APPROPRIATE LEVEL OF INTERVENTION

It is important to make an assessment of which level of intervention-individual/group or population-best addresses identified barriers and clinicians' stage of readiness to change before designing dissemination and implementation programmes. For example, it may be unnecessary to use national opinion leaders when most practitioners are already positively disposed towards a particular guideline. It may be important, however, to work at the local level with specific groups of practitioners where there is less support.

STEP 4: DESIGN OF DISSEMINATION AND

IMPLEMENTATION STRATEGIES

Strategies can be selected and designed on the basis of the above assessment. Although our conceptual framework distinguishes in some detail which strategies are likely to have the greatest impact in each stage of change, we do not intend to imply that, for example, the use of opinion leaders will only influence those practitioners in the pre-contemplation/ contemplation stage. Rather, it is theorised that the use of opinion leaders will have the greatest impact on individuals in this stage because strategies which aim to address the predisposing factors of attitudes and knowledge have been found to be important in the early stages of change.

STEP 5: EVALUATION

Evaluating the effectiveness of the implementation strategies in changing physician behaviour is a vital component of the process. Evaluation can also be used to assess how the strategies could be used in a hospital setting to implement change. The type of evaluation tool used will be dependent on the setting and type of implementation strategies used.

\section{Discussion}

Our framework builds on a substantive body of literature examining guideline dissemination and uptake, and draws on key elements of social and behavioural theory to assist in furthering understanding of these complex processes. We believe that each of the stages we have outlined could be linked to practical strategies to assist in guideline development and implementation efforts. For example, in a hospital setting, strategies might include: (1) inhouse surveys of personnel, perhaps in the form of personal interviews to assess readiness to change; (2) organisational barriers within an institutional setting could be assessed through interviews with key administrative and clinical staff; views of groups and individuals outside the immediate hospital environment, but with close referral relationships, could also be sought; (3) determination of appropriate level of intervention could be undertaken through careful analysis of material in steps 1 and 2 and further consultation with key decision makers within the hospital; (4) the design of dissemination and implementation strategies could take into account existing quality assurance or information dissemination strategies, or both, within the hospital; and (5) evaluation mechanisms could be built on existing audit and feedback mechanisms.

We emphasise that many of these steps are dependent on resources, but the steps we have outlined, drawing from social and behavioural theory, provide some guiding principles.

\section{Conclusion}

Our conceptual framework for guideline dissemination and implementation draws on various theoretical constructs discussed in this article. Pre-intervention assessment of practitioners' readiness to use guidelines is based on the transtheoretical model of behaviour change. Assessment of the specific nature of competency based, social, and organisational barriers to change draws on the ideas of Wensing and Grol, ${ }^{21}$ and discussion of constructs from health education theory, social influence theory, and social ecology theory helps to illustrate the importance of addressing these barriers. We also draw on the concept of targeting strategies to the individual/group or population level of intervention.

The potential value of the framework is that it may enable those involved in the process of guideline dissemination and implementation to target more effectively available strategies according to an assessment of stages of change and specific barriers to change. Targeting of strategies may be beneficial in many settings, especially those when time and money are of importance. Clearly, the effectiveness and utility of the model in facilitating guideline dissemination and implementation requires validation by further empirical research. Until such research is available, we believe it provides a comprehensive and workable theoretical framework that may assist in the process of selecting and more appropriately targeting dissemination and implementation strategies.

The authors would like to thank Dr Melanie Wakefield, Senior Behavioural Scientist, Epidemiology Branch, South Australian Health Commission, for her helpful comments on the manuscript.

1 Davies J, Freemantle N, Grimshaw J, et al. Implementing clinical practice guidelines: can guidelines be used to improve clinical practice? Effective Health Care 1994:8:1 12 .

2 Grimshaw JM, Russell IT. Effect of clinical guidelines on medical practice: a systematic review of rigorous evaluamedical practice: a systematic revic
tions. Lancet 1993;342:1317-22.

3 Oxman AD, Thomson MA, Davis DA, et al. No magic bullets: a systematic review of 102 trials of interventions to improve professional practice. CMAF 1995;153:1423-31.

4 Davis DA, Thomson MA, Oxman AD, et al. Evidence for the effectiveness of CME: a review of 50 randomised controlled trials. $\mathscr{F} A M A$ 1992;268:1111-17.

5 Davis DA, Thomson MA, Oxman AD, et al. Changing physician performance: a systematic review of the effect of continuing medical education strategies. FAMA 1995;274: $700-5$.

6 Grol R. Beliefs and evidence in changing clinical practice. BMF 1997;315:418-21.

7 Robertson N, Baker R, Hearnshaw H. Changing the clinical behaviour of doctors: a psychological framework. Quality in Health Care 1996;5:51-4.

8 Prochaska JO, Velicer WF, Rossi JS, et al. Stages of change and decisional balance for 12 problem behaviours. Health Psychol 1994;13:39-46. 
9 Firth-Cozens J. Healthy promotion: changing behaviour towards evidence-based health. Quality in Health Care towards eviden

10 Stocking B. Why research findings are not used by commissions and what can be done about it? Fournal of Public Health 1995;17:380-2.

11 Stocking B. Implementing the finding of effective care in pregnancy and childbirth in the United Kingdom. Milbank $Q$ 1993;71:497-521.

12 Schramm W, Lerner D. Communication and change: the last ten years and the next. Honolulu: University Press of Hawaii, 1978.

13 Rogers E. Diffusion of innovations. New York: The Free Press, Macmillan, 1983.

14 Rogers EM, Shoemaker FF. Communication of innovations: a cross-cultural approach. New York: The Free Press, 1971.

15 Macdonald G. Communication theory and health promotion. In: Bunton R, Macdonald G, editors. Health promotion: disciplines and diversity. London: Routledge, 1992 .

16 Conroy M, Shannon W. Clinical guidelines: their implementation in general practice. Br F Gen Pract 1995;42:371-5.

17 Felch WC, Scanlon DM. Bridging the gap between research and practice: the role of continuing medical education. FAMA 1997;277:155-6.

18 Hayward RSA, Wilson MC, Tunis SR, et al. Practice guidelines: what are internists looking for? F Gen Intern Med 1996;11:176-8

19 Prochaska JO, DiClemente CC. Stages and processes of self-change of smoking: toward an integrative model of change. F Consult Clin Psychol 1983;51:390-5.

20 Cohen S, Halvorson HW, Gosselind CA. Changing physician behaviour to improve disease prevention. Prev Med 1994;23:284-90.

21 Wensing M, Grol R. Single and combined strategies for implementing changes in primary care: a literature review. Int $\mathcal{f}$ Qual Health Care 1994;6:115-32.

22 Gupta L, Ward J, Hayward RSA. Future directions for clinical practice guidelines: needs, lead agencies and potential cal practice guidelines: needs, lead agencies and potential
dissemination strategies identified by Australian general dissemination strategies identified by Australian gen

23 Marshall MN. Qualitative study of education interactions between general practitioners and specialists. BMF 1998 316:442-5.

24 McColl A, Smith H, White P, et al. General practitioners' perceptions of the route to evidence-based medicine: a questionnaire survey. BMF 1998;316:361-5.

25 Green L, Kreuter M, Deeds S, et al. Health education planning: a diagnostic approach. Palo Alto, California: Mayfield Press, 1980.

26 Evidence-Based Medicine Working Group. Evidence-based medicine: a new approach to teaching the practice of medicine. FAMA 1992;268:2420-5.
27 Mittman BS, Tonesk X, Jacobsen PD. Implementing clinical practice guidelines: social influence strategies and practitioner behaviour change. Quality Review Bulletin 1992;18: 413-22

28 Haines A, Rogers S. Summary and future prospects. In: Silagy C, Haines A, editors. A guide to evidence-based health care. London: BMJ Publishing Group, in press.

29 Van Amringe M, Shannon TE Awareness, assimilation and adoption: the challenge of effective dissemination and the first AHCPR-sponsored guidelines. Quality Review Bulletin 1992 .

30 Day F, Hoang LP, Ouk S, et al. The impact of a guideline-driven computer-charting system on the emergency care of patients with acute low back pain. Annual Symposium on Computer Applications in Medical Care 1995: 576-80.

31 Thomson MA, Oxman AD, Haynes RB, et al. Outreach visits to improve health care professional practice and health care outcomes (Review). In: Bero L, Grilli R, Grimshaw J, et al, editors. Cochrane Collaboration on Effective Professional Practice Module of the Cochrane Database of Systematic Reviews (updated 3 June 1997). Available in the Cochrane Library (database on disk and CD ROM), issue 3. Oxford: Update Software; 1997. Updated quarterly.

32 Thomson MA, Oxman AD, Haynes RB, et al. Local opinion leaders to improve health professional practice and health care outcomes. In Bero L, Grilli R, Grimshaw J, et al, editors. Cochrane Collaboration on Effective Professional Practice Module of the Cochrane Database of Systematic Reviews (updated 3 June 1997). Available in the Cochrane Library (database on disk and CD ROM), issue 3. Oxford: Update Software; 1997. Updated quarterly.

33 Skinner B. The behaviour of organisms: an experimental analysis. New York: Appleton-Century, 1938.

34 Stokols D. Establishing and maintaining health environments: toward a social ecology of health promotion. Am Psychol 1992;47:6-22.

35 Elson RB, Connelly DP. Computerised patient records in primary care. Arch Fam Med 1995;4:698-705.

36 Johnston ME, Langton $\mathrm{KB}$, Haynes $\mathrm{B}$, et al. Effects of computer-based clinical decision support systems on clinical performance and patient outcome: a critical appraisal of the research. Ann Intern Med 1994;120:135-42.

37 Petrie JC, Grimshaw JM, Bryson A. The Scottish intercollegiate guidelines network initiative: SIGN-getting validated guidelines into practice. Health Bull 1995;53:345-8.

38 Lomas J, Haynes B. A taxonomy and critical review of tested strategies for the application of clinical practice policy. Am f Prev Med 1988;4:77-94. 